http://dx.doi.org/10.30681/23588403v12i03219234

\title{
GLOSSÁRIO DUCROTIANO
}

\author{
Hélio Ferreira MENDES JUNIOR (UNEMAT) ${ }^{1}$ \\ Solange Moreira dos Santos VELOZO (UNEMAT) ${ }^{2}$ \\ Wellington Marques SILVEIRA (UNEMAT) ${ }^{3}$
}

Resumo: Este glossário trata da Semântica Argumentativa no quadro geral dos estudos das significações linguísticas, com as filiações da Teoria da Semântica Argumentativa ou Teoria da Argumentação na Língua, as quais se iniciam com Platão, Saussure e Benveniste, e os conceitos, que a constituem, são discutidos a partir de três fases: $1^{\mathrm{a}}$ ) Forma Standard; $2^{\mathrm{a}}$ ) Teoria da Polifonia e Teoria dos Topoi; e $3^{\mathrm{a}}$ ) Teoria dos Blocos Semânticos, formulados por Anscombre, Ducrot e Carel. Nesse sentido, propomos com este glossário apresentar um esboço dos principais conceitos da Teoria da Argumentação na Língua, a partir das três fases que a constituem. Desse modo, esperamos que este trabalho possa servir de auxilio aos alunos de Graduação, Pós-Graduação e Professores e a quem interessar-se por este estudo. Sendo assim, passaremos a apresentar: a Forma Standard; a Teoria da Polifonia e a Teoria dos Topoi, e a Teoria dos Blocos Semânticos (TBS).

Palavras-chave: Glossário. Conceitos. Teorias. Topoi. Blocos Semânticos.

Abstract: This vocabulary deals with Argumentative Semantics in the general framework of the study of linguistic meanings, with the affiliations of Argumentative Semantic Theory or Argumentation in Language, which begin with Plato, Saussure and Benveniste, and the concepts that constitute it are discussed from three stages: 1st) Standard Form; 2nd) Theory of Polyphony and Theory of Topoi; and 3rd) Theory of Semantic Blocks, formulated by Anscombre, Ducrot and Carel.

In this sense, we propose with this vocabulary to outline the main concepts of the Theory of Language Argumentation, from the three phases that constitute it. Thus, we hope that this work can help the undergraduate, postgraduate and teachers students and those interested in this study. Thus, we will present: the Standard Form; Polyphony Theory and Topoi Theory; and Semantic Block Theory (TBS).

Keywords: Vocabulary. Concepts. Theory. Topoi. Semantic Block.

\footnotetext{
${ }^{1}$ Mestrando em Linguística -UNEMAT -Cáceres/MT, Brasil - e-mail: heliofmendes@ outlook.com

${ }^{2}$ Mestre em Linguística - UNEMAT - Cáceres/MT, Brasil - e-mail: mormsn@ hotmail.com

${ }^{3}$ Mestre em Linguística - UNEMAT - Cáceres/MT, Brasil - e-mail: wellingtonmarkis@ gmail.com
} 


\section{Lista de Siglas}

$\begin{array}{ll}\text { ADL } & \text { Argumentação na Língua } \\ \text { ANL } & \text { Teoria da Argumentação na Língua } \\ \text { CNRS } & \text { Centre National de la Recherche Scientifique } \\ \text { DC } & \text { (donc = portanto) } \\ \text { HEC } & \text { École des Hautes Études Commerciales de Paris } \\ \text { MD } & \text { Modificador Desrealizante } \\ \text { MR } & \text { Modificador Realizante } \\ \text { PUC- RS } & \text { Pontifícia Universidade Católica do Rio Grande do Sul } \\ \text { s. } & \text { substantivo } \\ \text { SA } & \text { Semântica Argumentativa } \\ \text { s.f. } & \text { substantivo feminino } \\ \text { s.m. } & \text { substantivo masculino } \\ \text { TAL } & \text { Teoria da Argumentação na Língua } \\ \text { TBS } & \text { Teoria dos Blocos Semânticos } \\ \text { UFRGS } & \text { Universidade Federal do Rio Grande do Sul } \\ \text { UNEMAT } & \text { Universidade do Estado de Mato Grosso } \\ \text { UNISINOS } & \text { Universidade do Vale do Rio Sinos }\end{array}$

\section{A primeira fase: Forma Standard}

A primeira fase da Teoria da Argumentação na língua encontra-se descrita em L'argumentation dans la langue (1983), pelos autores Jean-Claude Anscombre e Oswald Ducrot.

Neste momento da ADL, observa-se que as palavras não têm sentido antes das conclusões delas tiradas, ou, dito de outro modo, nesta forma tradicional, argumentação só ganha direcionamento a partir de uma conclusão específica. Trata-se, portanto, de considerar que o argumento $A$ funciona como um determinante, um doador de sentido para a conclusão $C$, orientando o direcionamento da argumentação na frase.

Observemos, tal como examina Freitas (2006, p.112), como se dá o sentido da argumentação a partir da frase a seguir:

Faz calor, vamos à praia.

$$
\text { A } \quad C
$$

Freitas (2006) nos mostra que o primeiro segmento, "faz calor", argumenta em direção ao segundo, "vamos à praia". Assim, percebemos que, tomando a frase como um todo, $A$ se torna 
incompreensível sem a relação deste com o argumento $C$. Isso porque os dois segmentos estabelecem uma relação de interdependência, ao passo que o argumento $A$ constitui-se em uma justificativa para o argumento $C$.

Em uma relação análoga à frase analisada acima, poderíamos estabelecer o mesmo tipo de relação a partir de sequências específicas, as quais se definem por " $A$ portanto $C$ " ou " $C$ em razão de $A "$.

Dessa forma, vale observar que a direção argumentativa, a partir da teoria tradicional, é orientada por dois princípios diferentes, tais como definição de (DUCROT, 1989, p. 16 em FREITAS, 2006, 113):

[...] a) o enunciado-argumento $A$ indica um fato $F$ (uma certa representação da realidade que possa ser julgada verdadeira ou falsa independentemente da intenção de, a partir dela, ser concluído $C$ ); e b) o produtor de $A$ admite ou supõe que o fato $F$ implica a verdade ou a validade da conclusão $C^{\prime \prime}$.

Sob essa perspectiva, nota-se que a forma Standard coloca em discussão a falsidade ou verdade de um argumento $A$ que, obrigatoriamente, implica em um estatuto de falsidade ou de verdade do argumento-conclusão $C$. Isso reforça a interdependência entre eles, equivalendo dizer que "[...] quando um discurso contém dois segmentos dos quais um é o argumento e o outro a conclusão, os dois segmentos constituem um só enunciado e isto porque o argumento somente tem sentido a partir da conclusão". (DUCROT, 1988, p. 75).

\section{A segunda fase: a Teoria dos Topoi e a Teoria Polifônica}

A Teoria da Polifonia defende a tese de que um enunciado comporta mais de um sujeito, e a Teoria dos Topoi tem como tese central a ideia de que a relação argumento-conclusão, que garante o sentido do enunciado, é mediada por um topos. (FLORES, 2009).

A teoria Polifônica, construída por Oswald Ducrot e desenvolvida, posteriormente, por colaboradores, mostra como Ducrot, em sua obra, se mostra inspirado em Charles Bally com a criação do conceito de polifonia, principalmente porque Bally formula, essencialmente, que a língua é um instrumento que permite a comunicação de um pensamento pela palavra. Essa leitura de Bally constitui premissas para a teoria polifônica, na medida em que, segundo o autor, há a possibilidade de que esse pensamento comunicado não corresponda ao sujeito 
falante, empírico, mas ao sujeito modal, havendo, assim, a possibilidade de que o mesmo sujeito falante possa comunicar outro pensamento, além do seu, pela palavra.

A própria natureza do signo impõe a Bally a possibilidade de dizer que o sujeito falante, até mesmo pela ironia ou pela mentira, pode comunicar um pensamento que não é genuinamente seu, mas outro que pode (ou não) estar em consonância ao seu. Barbisan e Teixeira (2002) observam ainda que a hipótese principal da teoria de Ducrot coloca que a argumentação é o fator essencial para a apreensão do sentido do enunciado, sendo que esse sentido está inscrito na língua. Para ele, a linguagem coloca a subjetividade do eu na interpretação, ou seja, o locutor expressa seu ponto de vista no discurso, por isso não é mais possível aceitar o caráter objetivo da linguagem.

Dessa forma, a argumentação é uma subjetividade inevitável, e das relações subjetivas e intersubjetivas depreende-se uma concepção enunciativa de linguagem, uma vez que se considera o eu-locutor/tu-alocutário no discurso. Nessa direção, o conceito de polifonia, segundo Ducrot, nasce das enunciações, porque a frase, abstrata e semanticamente com o valor da significação, não pode comportar locutor, nem enunciador. A frase indica possibilidades de sentido que podem ser construídas no enunciado, que é de natureza polifônica, pois conterá a matéria-prima utilizada para estabelecer os pontos de vista desses enunciadores constitutivos do sentido do enunciado.

Ao formular a teoria dos Topoi, Ducrot restringe a TAL à descrição do funcionamento dos operados argumentativos na língua. Assim para o autor, o topos limita os conjuntos de encadeamentos e certos argumentos e suas conclusões.

Na versão ducrotiana, o topos é um princípio argumentativo que ocupa um lugar comum na argumentação e orienta para uma conclusão, sendo regido por três propriedades:

a) Universalidade: marca o fato de o topos ser partilhado por uma coletividade da qual participam o "enunciador" e o "destinatário";

b) Generalidade: da universalidade decorre a generalidade. O topos é geral porque é válido tanto em situações de fala como em situações análogas, antes mesmo de se recorrer a ele;

c) Gradualidade: os topoi relacionam duas escalas, uma escala anterior $P$ em relação a uma escala posterior $Q$. Essas escalas são entendidas por Ducrot como a possibilidade de comparar o mais e o menos. 


\section{Revista de Estudos Acadêmicos de Letras}

Para exemplificar a questão abordada por Ducrot, segue o exemplo, conforme Elichirigoity (2007, p. 128):

Está fazendo $30^{\circ}$, vamos à praia.

Topos: O calor torna agradável a praia.

Nesse caso, teríamos as seguintes formas tópicas:

FT $^{1}$ - Quanto mais calor, mais agradável ir à praia.

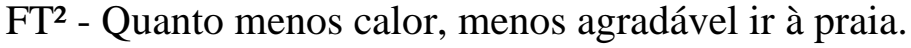

\section{A terceira fase: a Teoria dos Blocos Semânticos}

A Teoria dos Blocos Semânticos (TBS), conhecida como versão atual, ou ainda, como a terceira fase que constitui da TAL (Teoria da Argumentação na Língua), se desenvolve a partir da tese de Marion Carel, em 1992. A TBS preocupa-se em desenvolver e ampliar os conceitos fundantes da TAL, principalmente de que "a argumentação está inscrita na língua". Diante disso, (CAREL, 1997. In: FREITAS, 2006, 138) passa a questionar à Teoria dos Topoi, a qual defende a tese geral de que "o sentido de uma unidade linguística não é constituído pelos fatores extralinguístico, mas por alguns encadeamentos discursivos que ela evoca, a saber, "as argumentações": uma argumentação é um encadeamento do tipo X conector Y".

Sendo assim, a TAL é (re) formulada e ampliada por Marion Carel, em cuja versão o sentido argumentativo se constrói pela interdependência entre os seguimentos do encadeamento discursivo e não pela passagem do argumento à conclusão a partir de um princípio argumentativo o topos. (FLORES, 2017, p. 248). Dizendo de outra forma, é na terceira fase da Tal, ou seja, na versão atual da Teoria dos Blocos Semânticos, que Marion Carel, conforme Freitas (2006, p. 15), diz que: “é a interdependência entre os segmentos (argumento e conclusão) do discurso que constitui a argumentação".

Nessa direção, Freitas (2006) observa que o caráter argumentativo de um encadeamento pela interdependência semântica de seus dois segmentos distingue-se em duas estruturas básicas de argumentação: a normativa em donc e transgressiva em pourtant. Assim, essas duas estruturas são fundamentos argumentativos que constituem o discurso - donc e pourtant - e não mais uma-donc. 
Para Freitas (2006, p. 140), a Teoria dos Blocos Semânticos pode ser sintetizada nos seguintes tópicos:

- somente o discurso é doador de sentido, e, da totalidade dos discursos, os únicos que a TBS considera são os encadeamentos argumentativos;

- um encadeamento argumentativo é composto de dois segmentos, um argumento e uma conclusão, sendo que o sentido do encadeamento está na interdependência dos seus segmentos;

- por encadeamento argumentativo, Carel (2002) entende qualquer discurso sintaticamente analisável em duas frases que, de um ponto de vista semântico, sejam interdependentes e exprimam uma coisa única;

- os encadeamentos argumentativos são produzidos com base em duas estruturas prototípicas, $\mathrm{A}$ donc $\mathrm{C}$ e A pourtant non $\mathrm{C}$ e, nas duas, são estabelecidas relações de causa e consequência entre os segmentos argumento e conclusão.

Nesse sentido, o autor afirma que os encadeamentos em donc e os encadeamentos em pourtant são enunciados argumentativos, pois ambos convocam blocos semânticos, e são também encadeamentos elementares, por compartilharem interdependência entre si, ou seja, seguindo a mesma regra.

Tal como exposto pelos autores, algumas noções e ideias já formuladas por Saussure influenciaram e embasaram o trabalho de Ducrot, principalmente no que diz respeito aos princípios de uma descrição semântica da língua e à elaboração da Teoria da Argumentação na Língua.

\section{CONSIDERAÇÕES FINAIS}

A Semântica Argumentativa (SA), ou mais diretamente a Teoria da Argumentação na Língua (TAL), apresenta um retorno aos princípios estruturalistas saussurianos na medida em que, para dar contornos ao seu objeto de estudo (a língua), não opera com a referência ao mundo, ou seja, com a exterioridade e com fatores extralinguísticos.

Isso explica o porquê do retorno dessa teoria aos princípios de Saussure, pois leva em conta, nos trabalhos de Ducrot, Anscombre e colaboradores, que "[...] a argumentação está na língua, na própria natureza da linguagem, autorizando, pois, descrições lexicais. (DUCROT, 2001a). Desse modo, dizemos que esse princípio é percorrido pelas três fases da TAL, iniciado com a forma Standard e mantido pela Teoria dos Blocos Semânticos (TBS). Dessa maneira, este 
trabalho tem a finalidade de apresentar aos estudantes, professores ou interessados, num primeiro momento, alguns conceitos da Teoria da Argumentação na Língua por Anscombre, Ducrot e Carel.

\section{GLOSSÁRIO}

\section{A}

\section{Alocutário (1) s.m Ducrot}

Definição: aquele para quem as palavras do locutor são dirigidas.

Fonte da definição: FLORES, Valdir do N. et al. apud Ducrot, 2017. p. 47.

Nota explicativa: $\mathrm{O}$ termo alocutário (1) refere-se ao momento em que Ducrot vinculava seus estudos à Pragmática em 1980. Nessa época, postula, na noção genérica de interlocutor, a distinção entre os pares locutor/alocutário;

enunciador/destinatá-rio. Ex.: $\quad$ No enunciado "A ordem será mantida custe o que custar", supostamente dita por um ministro de Estado, em decorrência de desordens, realiza, segundo Ducrot, dois atos: o de promessa e o de ameaça. O locutor (inscrito no dizer do ministro) dirige-se ao alocutário (representado pelo povo em geral), produzindo os atos de promessa e de ameaça, respectivamente dirigidos a dois destinatários distintos: bons cidadãos e desordeiros.

Fonte da nota: Idem, p.48.

Termos relacionados: destinatário (1), interlocutor (1), locutor (2).

\section{alocutário (2) s.m Ducrot}

Definição: aquele que é linguisticamente representado no enunciado como alvo da enunciação.

Fonte da definição: FLORES, Valdir do N. et al. apud Ducrot, idem.

Nota explicativa: O Alocutário é um ser do discurso distinto do ser empírico (ouvinte). É indicado no enunciado como aquele a quem se dirige a enunciação. Por isso, o alocutário é intralinguístico como o locutor, e o ser empírico (falante ou ouvinte) é extralinguístico.

Fonte da nota: Idem.

Termos relacionados: enunciado (1), locutor, sujeito falante (2).

\begin{abstract}
Alteridade - Ducrot
Definição: Alteridade é um "valor constitutivo", ou seja, a alteridade constitui o sentido de um enunciado. Esta alteridade, por assim dizer "externa", uma alteridade "interna" colocando que o sentido de um enunciado descreve a enunciação como uma espécie de diálogo cristalizado, em que várias vozes se entrechocam (DUCROT, 1987, p. 9).
\end{abstract}

\section{Argumentação (1) s.f Ducrot \\ Definição: operação semântica- discursiva em que o sentido do enunciado é construído a partir de um segmento-conclusão, mediados por um lugar-comum argumentativo. \\ Fonte da definição: FLORES, Valdir do N. et al. apud Ducrot, 2017, p. 48.}

Nota explicativa: Essa definição de argumentação apoia-se na Teoria dos Topoi. Segundo essa teoria, a argumentação é construída pela relação entre os segmentos argumento $e$ conclusão e garantida por um princípio argumentativo, o topos, que estabelece a passagem de um segmento a outro. Fonte da nota: Idem, p.50.

Termos relacionados: argumento, conclusão, topos. 


\section{Argumentação Externa s.f Ducrot}

Definição: Pluralidade de discurso que podem seguir uma entidade lexical.

Fonte da definição: FLORES, Valdir do Nascimento et al. 2017, p.50-51.

Nota explicativa 1: Entidade lexical é concebida aqui como palavra ou expressão atualizada no discurso/enunciado.

Nota explicativa 2: Uma entidade lexical é evocada de modo externo se essa entidade constitui um segmento do encadeamento argumentativo. Se uma entidade lexical, como, por exemplo, ter pressa é o primeiro segmento do encadeamento argumentativo, o aspecto está relacionado a ela de modo externo à direita, e são assinaladas as consequências de ter pressa: ter pressa $\mathrm{DC}$ (donc = portanto) agir rapidamente. Se a entidade lexical ter pressa é o segundo segmento do encadeamento $\mathrm{o}$ aspecto está relacionado a ela de modo externo à esquerda: andar rapidamente DC $($ donc $=$ portanto $)$ ter pressa, em que é indicada a causa de ter pressa. Uma possibilidade de argumentação externa para a expressão ter pressa é ter pressa DC (donc = portanto) agir rapidamente. Nesse caso, a expressão ter pressa participa do encadeamento argumentativo.

Fonte da nota: Idem, p.50-51.

Termos relacionados: argumentação interna, aspecto, encadeamento argumentativo.

\section{Argumentação Interna s.f Ducrot}

Definição: encadeamento argumenta-

tivo que parafraseia uma entidade lexical.

Fonte da definição: Idem, p.51.

Nota explicativa 1: entidade lexical aqui é entendida como palavra ou expressão atualizada no discurso/enunciado.
Nota explicativa 2: Como a argumentação interna de uma entidade lexical é um encadeamento argumentativo que se constitui numa espécie de reformulação, essa entidade não é, ela própria, um segmento desse encadeamento. Ex: a argumentação interna de prudente é perigo DC (donc = portanto) precaução, que não contem a entidade lexical prudente.

Fonte da nota: Idem.

Termos relacionados: argumentação externa, aspecto, encadeamento argumentativo.

\section{Argumento s.m Ducrot \\ Definição: segmento do enunciado que orienta para uma conclusão. \\ Fonte da definição: Idem. \\ Nota explicativa 1: O argumento é definido como um segmento que juntamente com o segmento conclusão constitui o sentido do enunciado. Essa concepção aparece desde a chamada versão Standard da Teoria da Argumentação na Língua até a versão denominada Teoria dos Topoi. No exemplo "Faz calor lá fora, vamos passear", temos um enunciado constituído por dois segmentos, sendo o primeiro Faz calor lá fora argumento para o segundo vamos passear. Note-se que o sentido de calor só pode ser apreendido na relação entre os dois segmentos. Assim, calor nesse anunciado é favorável ao passeio. Se tivéssemos. Faz calor lá fora, não vamos passear, calor seria desfavorável a um passeio.}

Fonte da nota: FLORES, Valdir do Nascimento et al. 2017. p.51 apud Ducrot.

Termos relacionados: argumentação (1), enunciado (3), sentido.

\section{Aspecto s.m Ducrot}

Definição: classe de encadeamentos argumentativos de um mesmo bloco semântico. 
Fonte da definição: Idem, p.52.

Nota explicativa 1: Um bloco semântico, formado por estudar/ser aprovado, por exemplo, pode ser expresso no encadeamento argumentativo sob dois aspectos: o normativo com o conector do tipo geral de donc (= portanto), em que se tem "estudar DC (donc) aprovado", e o transgressivo com o conector do tipo geral de pourtant (= no entanto), em que se tem "estudar PT (pourtant) não ser aprovado".

Fonte da nota: Idem.

Termos relacionados: blocos semânticos, encadeamento argumentativo, regra.

\section{C}

\section{Componente linguístico s.m. Ducrot}

Definição: conjunto de conhecimentos que atribui uma certa significação a cada enunciado, independentemente de qualquer contexto.

Fonte da definição: DUC77; DUC87; EDU06. In: Ibidem, p. 62.

Nota explicativa: Constituída em momento anterior à Teoria da Argumentação na Língua, essa noção de componente linguístico, para Ducrot, faz parte da descrição semântica de uma língua. Sustenta-se na hipótese de que as ocorrências linguísticas precisam ser primeiro descritas através de um conjunto de conhecimentos, que exclui as circunstâncias nas quais são pronunciadas, chegando-se, desse modo, à significação.

Termos relacionados: contexto, enunciado (2), significação (2).

Conectores: Conforme Ducrot (2002), os conectores são entidades teóricas que estão "entre as palavras instrumentais", ou seja, entre (a) conectores: donc, pourtant; articuladores: conjunções; c) operadores: modificadores (роисо, um pouco, certos empregos de demais e fácil, como adjetivo); internalizadores (outros empregos do demais e quase todos os empregos de em vão). Cuja função é ligar dois seguimentos, orientando o discurso. Distinguem-se os "conectores", análogos a donc e a pourtant do francês, que servem para constituir discursos doadores de sentido que são os encadeamentos argumentativos. São construídas por conjunções semelhantes donc a, (portanto) e pourtant a, (no entanto), em português.

Fonte da nota: In: Flores (2006).

\section{D}

\section{Discurso s.m Ducrot}

Definição: O discurso é [...] a manifestação, a concretização do texto, entidade esta construída para explicar ou descrever o discurso, da mesma forma que a frase é um constructo criado pelo linguista para descrever suas ocorrências, os enunciados. Todo discurso está constituído por uma sucessão de enunciados. Se tenho um discurso D, este pode ser fragmentado nos enunciados e1, e2, e3 etc., e cada um desses enunciados é a realização de uma frase. (DUCROT, 1988, p. 53).

$\boldsymbol{E}$

\section{Encadeamento argumentativo - Carel (2005) e Ducrot (2005)}

Definição: Para Carel (2005) com a colaboração de Ducrot, o encadeamento argumentativo é "qualquer sequência de dois segmentos que são, de certo modo, dependentes".

(CAREL, 2005, 80). 
Nota explicativa: $\mathrm{O}$ termo encadeamento argumentativo é ampliado para Bloco Semântico, na terceira versão da Teoria da Argumentação na Língua, definida por Marion Carel desde (2002) como Teoria dos Blocos Semânticos - TBS, consistindo na ideia de interdependência semântica entre os seguimentos do encadeamento argumentativo.

Fonte da definição e da nota explicativa. (CAREL, 2005, p. 80). In: COSTA, Anna Carolyna Melo Ferrer. A teoria dos blocos semânticos, 2013.

\section{Enunciado s.m Ducrot}

Definição: Segundo o autor, o "enunciado" é um segmento de discurso, isto é, uma entidade que aparece num lugar e num momento dado e que não é, portanto, suscetível de ser repetido. Se eu disser a seguir "O tempo está bom. O tempo está bom", temos dois enunciados.

Nota explicativa: A significação de um enunciado é para Ducrot um objeto teórico: o que justifica recorrer a ela é seu valor explicativo, o fato de que ela torna possível uma certa regularidade, uma certa sistematicidade, na previsão do sentido das enunciações [enunciados].

Fonte da definição: (DUCROT, 1992, p. 228).

\section{Enunciação $s . f$ Ducrot}

Definição: a enunciação é a "realização de um enunciado, é um acontecimento histórico: é dada existência a alguma coisa que não existia antes de se falar e que não existira mais depois. É uma aparição momentânea, que não se repete. Conforme, o autor a enunciação se diferencia da frase, e de enunciado, porque ela possibilita três acepções: 1Atividade psicofisiológica implicada pela produção de um enunciado; 2Produto da atividade do sujeito falante; 3- Acontecimento constituído pelo aparecimento de um enunciado.

Nota explicativa: Ducrot explica que a primeira acepção da enunciação caracteriza-se por ser a atividade psicofisiológica envolvida na produção do enunciado. A segunda, o produto da atividade do sujeito falante, que é o próprio enunciado. A terceira, e a considerada pelo autor como adequada à descrição semântica que pretende realizar, é o acontecimento histórico que constitui o aparecimento do enunciado. Fonte da definição: (DUCROT 1980, p. 56 in FREITAS, 2006, p.111).

Enunciadores - Ducrot

Definição: são "seres que são considerados como se expressando através da enunciação, sem que para tanto se lhe atribuam palavras precisas: se eles "falam" é somente no sentido em que a enunciação é vista como expressando seu ponto de vista, sua posição, sua atitude, mas não, no sentido material do termo, suas palavras. (DUCROT, 1987, 192).

\section{$\boldsymbol{F}$}

\section{Forma Standard - Ducrot, 1988}

Definição. Encontra-se definida na obra L'argumentation dans la langue (1983), elaborada por Jean-Claude 
Anscombre e Oswald Ducrot. É a primeira fase da teoria e centra-se na ideia de que uma argumentação é necessariamente uma concatenação de dois segmentos do discurso: o argumento e a conclusão.

Fonte da definição: Ducrot (1988).

Nota explicativa: A Forma Standard (FS) foi substituída, mais tarde, pela Forma Standard Ampliada, composta pela Teoria dos Topoi e pela Teoria Polifônica da Enunciação. Tanto a Forma Standard quanto a Teoria dos Topoi foram contestadas por ferirem princípios que orientam os estudos desenvolvidos pela a Argumentação na Língua: a primeira feria o princípio da relação, ao tomar separadamente argumento e conclusão; e a segunda feria o princípio saussuriano da imanência da língua, ao inserir em seus pressupostos teóricos o conceito de topoi, ou princípio argumentativo, considerado como exterior à linguagem. Vejamos os exemplos:

a) Faz sol, vamos sair.

b) Faz sol, não vamos sair.

Nesses dois enunciados, o valor semântico da expressão: Faz sol varia, conforme as conclusões que se tirem dela. Num caso, o sol é favorável ao passeio; em outro, desfavorável.

Segundo Ducrot, o objetivo dessa concepção é analisar/descrever os casos em que um falante produz o enunciado A como argumento para justificar um outro enunciado C. Em português, isso se realiza por sequências do tipo "A logo C" ou "C já que A". (DUCROT, 1989, p.16. Trad. GUIMARÃES).

\section{Frase - s.f Ducrot}

Definição: Objeto teórico que constitui uma invenção da gramática, criação do linguista para explicar, do ponto de vista metodológico, os fenômenos da linguagem.

Fonte da definição: (DUCROT, 1981).

Nota explicativa: A reflexão sobre a linguagem, ou, de qualquer modo, sobre as línguas, é o primeiro passo para decidir que diferentes enunciados podem ser a realização de uma mesma entidade abstrata, definida na gramática da língua e que chamo "frase".

\section{$L$}

Locutor - s.m Ducrot, 1987.

Definição: De acordo com Ducrot entende-se por locutor um ser que é, no próprio sentido do enunciado, apresentado como seu responsável, ou seja, como alguém a quem se deve imputar a responsabilidade deste enunciado. Dizendo de outro modo, é o autor inscrito no sentido do enunciado e pode ser totalmente diferente do sujeito empírico, por exemplo, quando é um personagem fictício a quem o enunciado atribui à responsabilidade da sua enunciação.

Nota explicativa: É ao locutor que refere o pronome $\mathrm{eu}$ e as outras marcas da primeira pessoa. Mesmo que não se leve em conta, no momento, o discurso relatado direto, ressaltar-se-á que o locutor, designado por $e u$, pode ser distinto do autor empírico do enunciado, de seu produtor, mesmo que as duas personagens coincidam habitualmente no discurso oral. Há de fato caso em que, de uma maneira quase evidente, o enunciado, como 
aquele a quem se deve atribuir a responsabilidade da ocorrência do enunciado (DUCROT, 1987, p.182).

\section{M}

\section{Modificadores - Ducrot , 1995}

Definição: os modificadores são certos tipos de palavras como: (adjetivos e advérbios) que acompanham os predicados da língua (nomes e verbos), justificando de um ponto de vista linguístico, que tais modificadores aumentam e diminuem a força argumentativa de um predicado. São esses modificadores denominados, na Teoria, de realizantes e desrealizantes. que funcionam como modificador agindo sobre a força argumentativa de outra palavra. Ainda conforme, o autor essa noção está ligada à fase da ampliação da Teoria da Argumentação na Língua e à questão dos topoi em que Ducrot mostra que certos fatos da língua atestam a gradação intrínseca dos predicados.

Nota explicativa: $\mathrm{Na}$ Teoria da Argumentação, Ducrot (1995, p.145) aponta certo tipo de palavras que funcionariam como um modificador agindo sobre a força argumentativa de outra palavra.

\section{$\boldsymbol{P}$}

\section{Palavras instrumentais}

Definição: São aquelas as quais não queremos ou não podemos associar um conjunto específico de aspectos e de discursos. Isso não significa que seu valor semântico seja estranho à ordem do discurso. Simplesmente ele se define em relação a discursos que não lhes são propriamente ligados.

Fonte da definição: Ducrot, 2002.

\section{Palavras plenas - Ducrot}

Definição: Conforme Ducrot, não se pode atribuir a uma $\mathrm{AE}$ e uma $\mathrm{AI}$ todas as palavras do léxico. No entanto, isso é possível àquelas chamadas habitualmente de "palavras plenas", que se caracterizam pelo fato de possuírem um conteúdo. Ou seja, são aquelas que têm em comum evocar discursos que pertencem aos aspectos que constituem sua $\mathrm{AE}$ e sua $\mathrm{AI}$.

Fonte da definição: Idem, 2002.

$S$

\section{Sentido - s.m Ducrot}

Definição: Do ponto de vista da Semântica, Ducrot chama de "sentido" o valor semântico que um ouvinte [...] atribui a um enunciado, em outros termos, à interpretação que lhe atribui um testemunho, independentemente se ele estiver fora do processo de comunicação ou envolvido nele, e, neste caso, se ele for ativo (locutor) ou passivo (alocutário).

Fonte da definição: (DUCROT, 2017, p. 113). Trad. Koman \& Dornas (2017).

\section{Significação - Ducrot}

Definição: Para Ducrot, a "significação" é reservada para o valor semântico da frase; tal como a frase, ela pertence então à língua e, enquanto tal, exerce um papel central em toda semântica linguística. Ainda nessa perspectiva, o autor coloca que a significação não se encontra no sentido como parte sua: ela é, no essencial pelo 
menos, constituída de diretivas, ou ainda de instruções, de senhas, para decodificar o sentido de seus enunciados.

Fonte da definição: (DUCROT, 2017, p. 113). Trad. Koman \& Dornas (2017). \& (DUCROT, 1989, p. 14).

\section{Sujeito Falante - Ducrot, 1987}

Definição: Ducrot (1987) afirma que o sujeito falante é um elemento da experiência [...] um ser empírico.

\section{$T$}

ANL: a Teoria da Argumentação na Língua (ADL), também conhecida pelos autores como ANL, é definida conforme Zoppi-Fontana (2006, p. 195) como "uma abordagem desenvolvida dentro do campo da linguística e que se propõe descrever a argumentação com base nos elementos da língua que possibilitam seu funcionamento". Trata-se, portanto, segundo a autora, de que ADL ou ANL "é uma teoria segundo a qual a argumentação está inscrita estruturalmente na língua, especificamente no léxico". É importante observar que a ADL assume uma abordagem não referencialista da significação. A ANL conta com três fases no seu desenvolvimento: a primeira fase: forma standard (1983); a segunda fase: a Teoria dos Topoi e a Teoria Polifônica da Enunciação (1990); a fase atual: a Teoria dos Blocos Semânticos (TBS). (FLORES apud DUCROT, 2017, p. 249).

Nota explicativa: Conforme Dall'Cortivo-Lebler (2014, p.332), na introdução do seu artigo "A teoria da Argumentação na Língua e sua relação com Platão, Saussure e Benveniste: breve discurso epistemológico", diz que a ANL se inicia em meados de 70 , com a publicação da obra Escalas
Argumentativas, por Oswald Ducrot. A autora ainda afirma que "essa teoria se constitui num conjunto de reflexões amadurecidas pelo autor que, filósofo e matemático, abraçou a ciência linguística no início de sua carreira, primeiramente ao entrar em contato com o estruturalismo, por ocasião de um curso preparatório para a École des Hautes Études Commerciales de Paris (HEC) e, posteriormente, ao ser admitido no Centre National de la Recherche Scientifique (CNRS) para uma tese em história da filosofia". (DALL'CORTIVO-LEBLER, 2014, p. 332).

Teoria dos Topoi: consiste na segunda fase da ANL, que já tinha como princípio a explicação do sentido da língua com base em encadeamentos argumentativos, que seriam a realização discursiva daquilo que habitualmente se chama "argumentações", ou seja, a relação entre um argumento e uma conclusão. Um segundo elemento adicionado à composição da ANL, que a transformaria na Teoria dos Topoi, veio da retórica aristotélica, com o topos. (DUCROT, 1999, p. 5).

Teoria Polifônica da Enunciação: Tal concepção enunciativa do discurso tem importância na medida em que "sempre que se fala se fala de sua fala" (DUCROT, 1980a, p. 40), ou seja, o dito denuncia o dizer. A TAP tem por objetivo incorporar às suas explicações sobre o uso da língua "algumas pistas para a descrição de certos fenômenos que mostram alusões do enunciado a enunciações diferentes da sua" (CAREL DUCROT, 2010, p. 9); e 
opõe-se à ideia de unicidade do sujeito falante, na medida em que prevê o desdobramento do sujeito falante em três funções distintas: a de sujeito empírico, a de locutor e a de enunciador (mais recentemente substituído por Carel e Ducrot (2010) pelo conceito de Pessoa).

Texto: Para a Semântica Argumentativa, o texto constitui-se como "entidade abstrata e complexa, é uma sequência de frases" (FREITAS, 2006, p.20).

\section{Topos s.m. DUCROT}

Definição: um princípio argumentativo que ocupa um lugar comum na argumentação garantindo a passagem do argumento à uma conclusão. $\mathrm{Ou}$ seja, um princípio argumentativo que possibilita a articulação entre um enunciado-argumentativo e um enunciado-conclusão, imprimindo aos enunciadores, através dessa articulação, uma dada orientação argumentativa.

Fonte da definição: (DUCROT, 1988. In: FREITAS, 2006, p. 129).

Nota explicativa: o topos é regido por três propriedades: a universalidade, a generalidade e a gradualidade. A universalidade ocorre devido ao fato de ele ser um consenso no seio de uma coletividade; a generalidade porque vale para situações diferenciadas daquela em que é utilizado e a gradualidade porque a relação argumento/conclusão é gradual por natureza, pelo fato de que um argumento é mais ou menos forte para uma dada conclusão.
V

Valor argumentativo: $\mathrm{O}$ valor argumentativo de uma frase não é somente uma consequência das informações por ela trazidas, mas a frase pode comportar diversos morfemas, expressões ou termos que, além de seu conteúdo informativo, servem para dar uma orientação argumentativa ao enunciado, a conduzir o destinatário em tal ou qual direção.

Fonte da definição: (DUCROT, 1981, p. 178). 


\section{REFERÊNCIA}

ANSCOMBRE, Jean Claude. (Or). Théorie des Topoi. Paris: Éditins Kimé, 1995.

Argumentação e topoi argumentativos". In: GUIMARÃES, Eduardo. (ed.).

História e sentido na linguagem. Campinas: Pontes, 1989.

A interpretação em semântica linguística: um ponto de partida imaginário. [Trad. bras. de L'interprétation en sémantique linguistique: un point de départ imaginaire]. Entremeios [Revista de Estudos do Discurso, on-line], Programa de Pós-Graduação em Ciências da Linguagem (PPGCL), Universidade do Vale do Sapucaí (UNIVÁS), Pouso Alegre (MG), v. 14, p. 111-134, jan. - jun. 2017. DOI: disponível em: $\quad$ http://dx.doi.org/10.20337/ISSN21793514revistaENTREMEIOSvol14pagina111a134 Acesso em: 02 ago. 2017

BARBISAN, Leci Borges; TEIXEIRA, Marlene. Polifonia: origem e evolução do conceito em Oswald Ducrot. Organon, v. 16, n. 32-33, 2002.

CAMPOS, Claudia Mendes. O percurso de Ducrot na teoria da argumentação na língua. In: Revista da ABRALIN, v. 6, n. 2, p. 139-169, jul./dez. 2007.

CAREL, Marion; DUCROT, Oswald. La semântica argumentativa. Una introducción a la teoría de los bloques semánticos. Trad. e edição Maria Marta Garcia Negroni e Alfredo M. Lescano. Buenos Aires, Ediciones Colihue, 2005.

COSTA, Anna Carolyna Melo Ferrer. A teoria dos blocos semânticos. $97 \mathrm{f}$. Dissertação (Mestrado em Letras) - Programa de Pós-graduação em Letras da Universidade Federal do Paraná - UFPR. Curitiba, 2013. Disponível em: http://www.acervodigital.ufpr.br/handle/1884/31772 Acesso em: 02 ago. 2017.

DALL'CORTIVO-LEBLER, Cristiane. A teoria da argumentação na língua e sua relação com Platão, Saussure e Benveniste: breve discussão epistemológica. Filologia e linguística portuguesa, v. 16, n. 2, p. 331-364, 2014.

DUCROT, Oswald. Provar e dizer. Leis lógicas argumentativas. São Paulo: Global, 1981.

DUCROT, Oswald. Polifonía y argumentación. Conferencias del seminario Teoria de la Argumentación y Análisis del Discurso. Cali: Universidad del Valle, 1988.

165.

Os modificadores desrealizantes. Journal of Pragmatics 24, 1995, p. 145-

Os Topoi na Teoria da Argumentação na Língua. Revista Brasileira de Letras. 1999,1(1).

Prefácio. In: VOGT, Carlos. O intervalo semântico. 2. ed. São Paulo: Ateliê Editorial/Campinas: Editora da Unicamp, 2009b.

setembro, 2002.

“Os internalizadores". In: Letras de Hoje. Porto Alegre, v. 37, n. 03, p. 7-26, 
Polyfonia y argumentación. Conferencias del seminário Teoría de la Argumentación y Análisis del Discurso. Universidad del Valle. Cali, Colombia, 1988. Trad. Neuza Zattar (2017).

Esboço de uma teoria polifônica da enunciação. In: DUCROT, O. $O$ dizer e o dito (1984). Campinas: Pontes, $1987 \mathrm{~b}$.

FLORES, Valdir do Nascimento. Dicionário de linguística da enunciação [et al.]. (Orgs.). Valdir do Nascimento Flores [et al.]. São Paulo: Contexto, 2017.

FREITAS, Ernani Cesar de. A teoria da argumentação na língua: blocos semânticos e a descrição do sentido no discurso. Tese (Doutorado em Letras). PUC/Porto Alegre, RS, 2006.

GRAEFF, Telisa Furlanetto; COSTENARO, Silvane. Análise de mal-entendidos em diálogos. In: Calidoscópio. V. 7, nº 2, p. 155-160, Unisinos-RS, mai/ago 2009.

SILVA, Carmem Luci da Costa. "A argumentatividade na fala infantil". In: Organon, v. 32, n. 33, p. 117-118, 2015.

SILVÉRIO, Sandra Mara. A noção de modificadores na teoria da argumentação e uma análise de adjetivos no português. Working Papers em Linguística, n. 1, p. 109122, 1997.

RÖRIG, Cristina; BARBISAN, Leci Borges. A Enunciação na Teoria da Argumentação na Língua. Anais do III Mostra de Pesquisa da Pós-Graduação PUCRS. Porto Alegre: PURCRS, p. 1058-1060, 2008. Disponível em: Https://scholar.google.com.br// . Acesso em: 08/08/2017.

ZOPPI-FONTANA, Mônica. "Retórica e argumentação". In: LAGAZZIRODRIGUES, Suzy; ORLANDI, Eni P. (Orgs.). Discurso e Textualidade. Campinas: Pontes, 2006. p. 179-21 